\title{
Narrative and the space of digital architecture: implementing interdisciplinary storytelling in the design of interactive digital space
}

\author{
J. Maze \\ School of Architecture, University of Florida, USA
}

\begin{abstract}
This abstract and the resulting paper explore the ideas of narrative and context as generative tools in the digital design process. This is the initial premise of an interdisciplinary graduate seminar taught at the University of Florida between the Schools of Architecture, Fine Arts, and Computer Science and Engineering. The resulting design narratives will be discussed and evaluated. The different types of narrative - conceptual, plot based, etc. - will be examined and new types of interactivity will be proposed and tested.
\end{abstract}

Keywords: digital modelling, narrative, design education, animation, virtual space.

\section{Introduction}

"Door, window, stair... once upon a time..." The power of storytelling set in stone and steel is one of the most powerful attributes of architecture. Architecture is the ultimate portrayal of a narrative. It is physical, interactive, and permanent. It is a real time immersive experience that can be enjoyed by multiple readers simultaneously. It is a story. Storytelling is not typically thought of as the role of the architect, but truth be told, the ability to guide and shape one's set of experiences through design is arguably the most impacting of narrative devices. Architecture tells the tale of the values or identity of its patrons and place, knitting together an understanding of its particular situation within a set of contexts and the spatial language of inhabitation. How one is choreographed upon entry of a designed environment and led through as though a character in a carefully scripted plot is the ability of architecture to tell a tale, moreover an interactive tale. 
The word narrate stems from the Latin narrare, which in turn stems from the Indo-European gnarus which means "to know." The first implication of this root is that to narrate one must possess knowledge of something. The second implication is that the act of narration can be a passive act of possessing knowledge and allowing for it to be uncovered; that is the knowledge or lesson to be shared can be availed to the reader in a non-active way. The term has come to mean the active conveyance of a story or information by a narrator: one who tells a story or gives an account of something - a raconteur. What is explicit though in the etymology of the term is that there is a relationship between the transmitter of conveyance and its receiver. There must be an engagement of some sort that bridges the space between them so that the story can be shared. In doing so, the space of the narrative is simultaneously occupied by both. In oral traditions, this is often accomplished through song as the narrative vehicle.

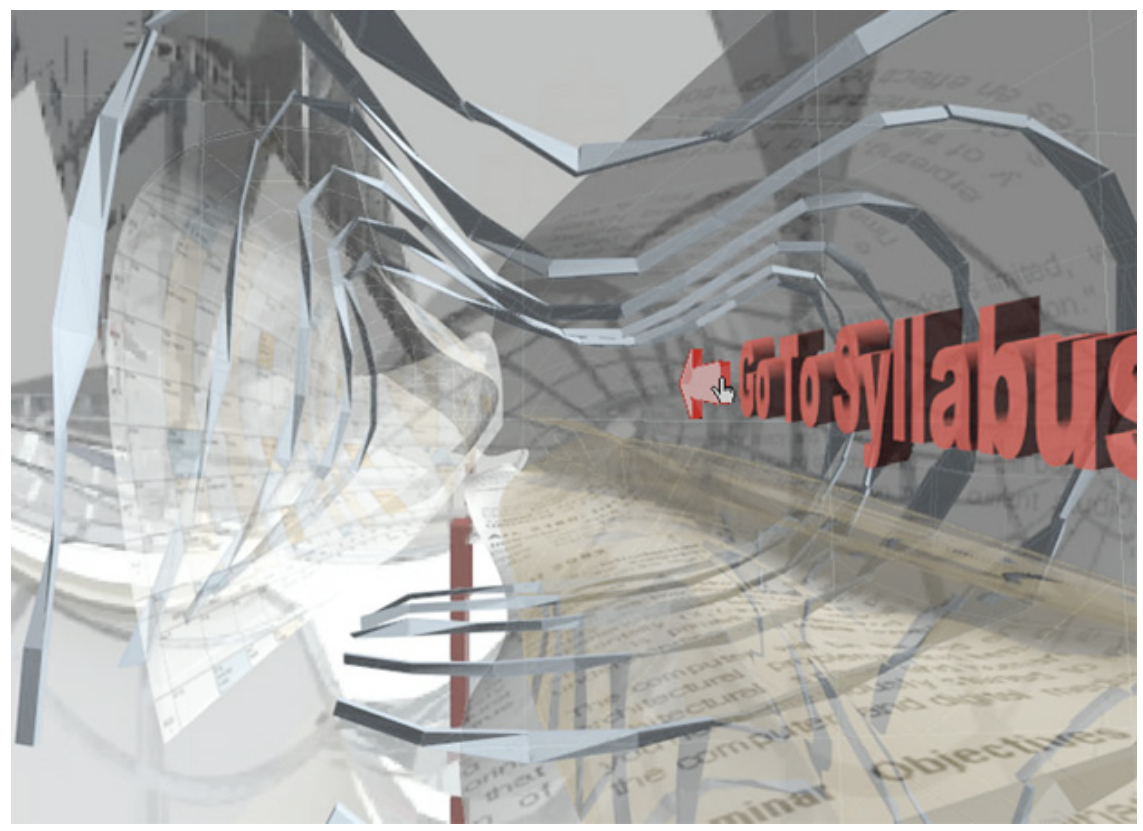

Figure 1: Virtual narrative space serving as the webspace for a digital architecture class. Assignments, syllabus, and project gallery are interactive navigated using VRML and QTVR.

\section{Narrative typology}

There are many possible types of narratives ranging from the most mundane newscast to the most involved epic poem. In an attempt to clarify the intentions of fine arts and architecture students at the University of Florida who are developing spatial narratives, possible narrative schemas are categorized into the 
following list. By defining the narrative typology of how an idea can best be presented, one can craft the narrative more accurately. The following list is not intended to be all-inclusive.

\subsubsection{Scenario: action based}

The most widely familiar narrative is the plot or action-based type. The story unfolds through the actions of a protagonist (e.g. an actor or character in a book) or through choices made by the user, who assumes the first-person role of protagonist (i.e. videogame). The particular perspective offered is that seen through the eyes of the protagonist, or in the case of storytelling, it is typically through the eyes of the narrator that may take on a third-person perspective.

\subsubsection{Allegorical: metaphorical}

A particular idea can be conveyed in the form of a story, or an allegory in which the meaning behind the words is not as direct as with a plot-driven narrative. There is a concept that can be explored and expressed by virtue of the quality of the descriptions placed into the narrative structure.

\subsubsection{Artistic: impressionistic}

The artistic narrative expends its energy in description alone. There is a perceptual lens through which the reader experiences the imagery described by the narrative vehicle. Interpretation of the substance communicated is required by the reader to make sense of it.

\subsubsection{Informative: instructive}

Knowledge communicated in a straight forward manner for the purpose of instructing others can be categorized as informative or instructive. The information ticker visible on CNN broadcasts, or the New York Stock Exchange ticker does just this without any sort of editorial overlay. The NYSE stocks page in the business section of most newspapers follows this same example, which is to deliver the prices as clearly and concisely as possible.

\subsubsection{Spiritual: value-based}

The Old Testament of the Judeo-Christian faith conveys a set of lessons about morality, faith, and honesty in the form of historical accounts of early human history. Without discussing the specifics of the several books that comprise the Old Testament, it demonstrates the overlay of spiritual attitudes on otherwise straightforward scenario-based narrative. The New Oxford Annotated Bible published in 1962 includes a subtext at the bottom of each page that recounts the information of the original King James translation in a clear, factual manner. It almost reads as a history text without the valuative and spiritual overlay, and is an interesting comparison to the original text above. Many non-religious childhood stories present at the end the phrase "and the moral of the story is..." demonstrating that there is a lesson to be learned by reading or listening to the story. This is the real narrative. The scenarios that serve as the vehicle to share this narrative are secondary to the message that is intended to educate. 


\section{Narrative in architecture}

Narrative instils meaning. Architecture tells tales that we move through as characters. This spatial tradition is less fluid than an oral tradition, but is even more powerful because all of the senses are engaged as one is moved and guided through space. Often students get caught up in the latest theory or conceptual jargon (myself of course very guilty of this) and forget the simple joy of shaping ones spatial experience via an architectural journey. The sequence of spaces encountered and the quality of those spaces tells a tale the way a filmmaker shapes ones understanding of a narrative frame for frame. According to filmmaker turned architect Rem Koolhaus "there is surprisingly little difference between one activity and the other... I think the art of the scriptwriter is to conceive sequences of episodes which build suspense and a chain of events... the largest part of my work is montage... spatial montage" [1].

All that is placed within the design of a space speaks to the intentions, the desires, the values of the designer; or at least it can and perhaps should represent the idiomatic qualities of the designer, client, or both. The way that light is sculpted, the manner in which the space is entered and experienced, the materials that make up the enclosure and its contents all have the potential to evoke meaning far beyond just utility. The spirit of the place and time is conveyed by virtue of the choice of materials available, and the technology used to erect it. The regional climatic needs can be represented in the size and placement of apertures, the threshold condition upon entering the space, and the shape and height of ceiling and walls. Though the advent of electronic climate control systems, the mass production of building materials, and the global systemization of building practices all diminish the potential for these phenomenological factors to be quietly incorporated into the design of most spaces, the possibility is still there.

Architecture forms a series of possibilities that can be explored by the user/reader. The plot is played out by those who enter and allow their destinies to be dictated by the architectural syntax: walls, doors, stairs, windows, etc. This syntax structures the architectural journey through space and time, and presents the reader with a series of decisions. Each decision helps the plot - the narrative - to unfold and develop accumulatively. The story becomes entirely interactive by virtue of the sometimes-unforeseen outcome of the decisions made while navigating through the architectural journey. The architecture can use other narrative tools in its roll as storyteller such as foreshadowing, flashback, and suspension of disbelief.

\section{What is virtual architecture}

Virtual architecture is defined as the process of ethical and appropriate designing in cyberspace in a fashion specific to its context. The appropriateness of the design is important as the design determinants in this virtual world devoid of worldly materiality, gravity, and natural phenomena (i.e. rain and wind) call for a different set of principles for the creation of space. There is no need for 
architectural necessities such as floors, roofs, and stairs, so the design syntax is quite different. Representations of buildings or physical constructions have no place in this world, and are as such not ethical to the context of cyberspace.

"Virtual spaces that mimic real buildings, as in a virtual Barcelona Pavilion or Palace of the Soviets, call to mind the difference between Normal Rockwell and Mark Rothko. Both are painters, yes, but Rockwell the realist raised the bar on illustration, while Rothko, the abstractionist, perfected canvases that profoundly influence the way we see the world. Obviously, I believe that virtual space has to be about the latter achievement and not a mere reflection of our world as we know it; it's a deep study of possibilities and the unknown" [2].

In the beginning, the digital interface was strictly one-dimensionally textbased. Prior to the invention of the Graphic User Interface (GUI), data was entered into the computer via punch cards. This evolved into a text-based system that used a keyboard, and was the standard for decades until the early 1980s when Xerox developed a new system that employed a mouse to navigate across a two-dimensional screen replete with graphical icons. This is still the standard used nearly two decades later. Of course, the spatiality of the interface will always continue to evolve. Microsoft has developed and is currently testing a three-dimensional interface, where the lexicon of flat icons and windows has segued into three-dimensional objects and spaces. What logically follows is the venture into a four-dimensional interface, where space is constructed with moving images. Suffice it to say that there is a concerted effort to emulate qualities of the physical world in the digital context. The state of the art in digital interfaces is three-dimensional, so it should follow that the context of virtual environmental design is three-dimensional. Gradually more and more websites will become webspaces as the advantages of a less-flat delivery environment become more apparent.

\section{The narrative and virtual architecture}

Part of the challenge of developing narrative virtual spaces is that there has been a shift towards more of an image-based tradition from one that has traditionally been oral. Technological shifts in how we communicate has aided in this demise of orally transmitted knowledge, as have changes in cultural values, economical apparatuses, and building traditions. More and more, we do not place as high of a value on narrative as a concept as we once did, choosing instead more immediate means of communicating and being entertained such as the internet, news broadcasts with simultaneous streaming tickers of current events, and reality television. Obviously the time of families gathering around the radio for the nightly broadcast or telling stories around the fire are gone, so in avoiding a nostalgic retreat, we shall suffice it to say that the attention span of the emerging global community is growing shorter by the second and with this decline in communicative engagement, the way in which we regard other humankind is suffering.

Architecture involves physicality in its engagement of the viewer, what then happens to the narrative style and syntax to tell a story if the architecture is 
purely digital? Since three-dimensional modelling environments became the norm in the practice of architecture, speculation has occurred about the ability to design virtual realms that are not of the corporeal world, but of a world of pure data. The context of course is vastly different as is the type of architectural response to it. The engagement of the body is quite limited in most cases to these senses of sight and hearing, so in order for the architect to narrate with design, the architecture of walls, doors, and floors will not be adequate because the body will not inhabit this digital environment. So what is the resulting architectural language needed to convey the same magnitude of storytelling?

Day to day GUI use involves vast quantities of image and text information to be sifted through in order to acquire knowledge. This is the current reality of the World Wide Web. At some point a decision had to have been made during the creation and evolution of the web to make it more image based as in print media rather than spatial as in the physical world. Even news broadcasts have started to move in this flattened direction as more and more textual and image-based tickers of information are scrolled across the screen, even at times obscuring the view of the newscaster sitting space broadcasting the information to us. Little argument could be made to the postulate that human kind is moving away from an oral (interactive and spatial) based tradition of communication to one that is based primarily in the immediacy of an image (fixed and sedentary).

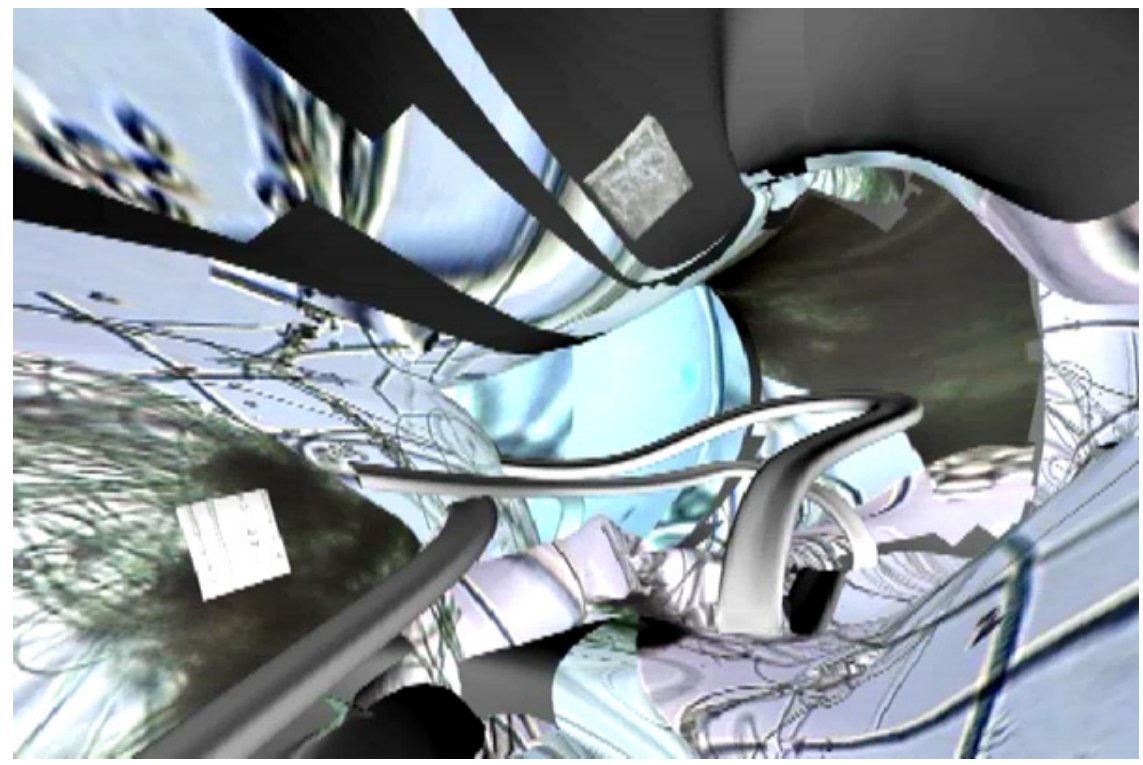

Figure 2: Digital narrative environment exploring the phenomenological experience of water by Eric Peterson and Marie Marberg.

\subsection{Narrative structure in the virtual realm}

There are five primary layers to the virtual narrative space, each necessary for the first-person portrayal of the intended spatial experience. Each of these works 
in concert with the others to produce an immersive experience for the user that captivates the imagination and titillates the senses. This can be seen as similar to the requisite components of theatre that include the set, the lighting, the make up, the costumes, and the script, all of which support the actors who play out their parts.

In the cinematic traditions, these dramatic determinants have an additional set of layers that help to shape the overall perception of the film. This governs the intermediary vehicle for the user to be engaged by the narrative: the camera. Film is conceived to shape the environment of the narrative for the space of the camera. Instead of the audience member being able to have perceptions of the action on stage specific to the location of the seat, by shaping the story for the space of the camera each audience member receives a nearly identical portrayal of the narrative. The subtlies of camera angle, camera movement, focal length and depth of field all shape the perception of the piece. In addition, film type and speed also shape the final collection of images. Various film types have idiomatic colorations and qualities that can be used to create moods and overall thematic content in the piece beyond what is available through the actors and other primary elements of the narrative. In recent years, post-production offers a new array of layers to the narrative structure. Special effects and computer generated wizardry add a new array of layers to convince us that the action on the screen is "real" and that we should feel engaged in the narrative.

For the purposes of clarity, assume that there are five layers that constitute the perception of a virtual narrative. These work together to create an environment of engagement and interplay. There is some overlap between some of these layers, but each does posses its own independent specificity when crafting the narrative environment. Each can individually sway the perception of the space in ways that the other cannot, but do all coalesce in a gestalt not otherwise possible.

\subsubsection{Backstory}

The "backstory" is essentially the untold story of why the encountered spaces are the way that they are. A lot of the fundamental meaning inherent to the virtual space can be described in this manner. It is also helpful in describing why the user is "there" in the first place. Myst, the widely popular and influential game operates almost entirely within the backstory, supporting it with the design of the environment. The user finds oneself in an environment with no immediatelyknown purpose, and has to piece together the story through subtle clues found within. Only over time and experience is the backstory revealed so that action can be taken to resolve issues that it created.

\subsubsection{Narrative overlay}

The "overlay" is the particular lens through which the perception of the narrative space is portrayed. This is the general attitude about or the take on the circumstances that make up the space, and adds a certain bend to the narrative. An example could be an environment that is devised to be a spatial journey into and through a mandala, a spiritual meditative painting. The overlay is that the journey is transcendental and recalls a hallucinogenic trip. This fact, once 
realized, shapes the reaction of the user to the environment that is encountered. It helps define the logic, perhaps hidden, governing the design of the virtual space.

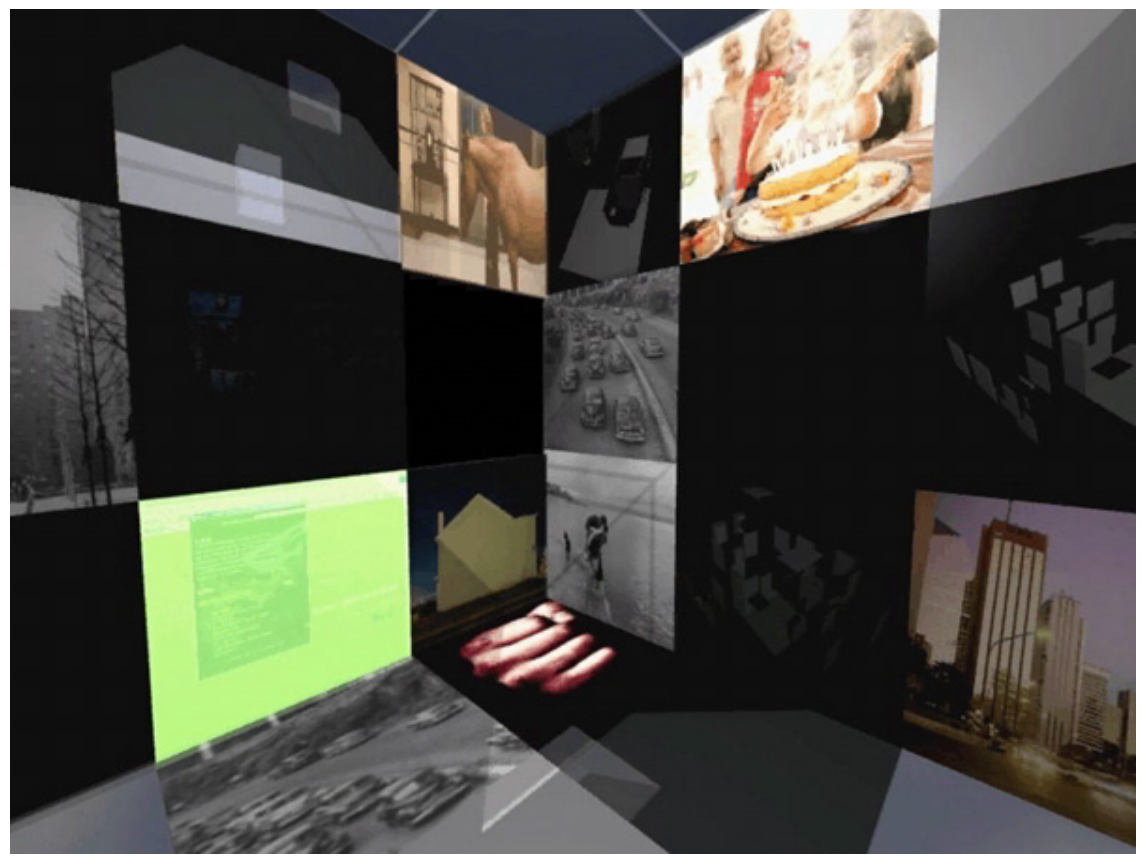

Figure 3: Digital narrative environment based on the writing of French scholar Gaston Bachelard by Sean Williams and Paul Girello.

\subsubsection{Environment}

The "environment" is of course the perhaps most defining element of the narrative. The spaces in which the story unfolds have to be designed in such a way that the other layers do not have to be too heavily wrought to carry the virtues and action of the navigation. This is the architecture of the space; that is to say the specific relationships between various spatial experiences and the qualitative nature of each. One must decide carefully the overall language of the spaces and how is it tied into the structure of the narrative. How one produced the lighting and materials of the environment sets the mood and tone of the story.

\subsubsection{Navigation}

The "navigation" typology governs how the experiences are laid out for the user. Whether one is allowed to move freely throughout the designed environment or is contained within a certain trajectory strongly shapes the perception of the place and that within. There is a big difference between moving through a virtual space in the first-person (i.e. viewing it from the vantage point of an inhabitant) and finding one's way through in the third-person (i.e. by moving a character through from outside the environment as in a plan). 
Examine the difference between "exploring" and "navigating" space. The former implies to set out on a journey to discover new things, to venture into the uncharted waters of the unknown. The latter implies to find one's way through charted waters, to use direction-finding cues found along the journey to aid in arriving at one's intended destination. Similar terms that in the computer vernacular have become one in the same, although the essence of what each term means is quite the opposite of the other. Yes, each means to set out on a journey, but one relies on the records of those who have gone first. As ubiquitous as these terms are in our day to day lives surfing the net or searching for data, each appeals to a different mindset for how space is to be transversed. In the digital realm, if one were to embrace the terminology, the way in which datasets are made available to the user/reader would be quite different.

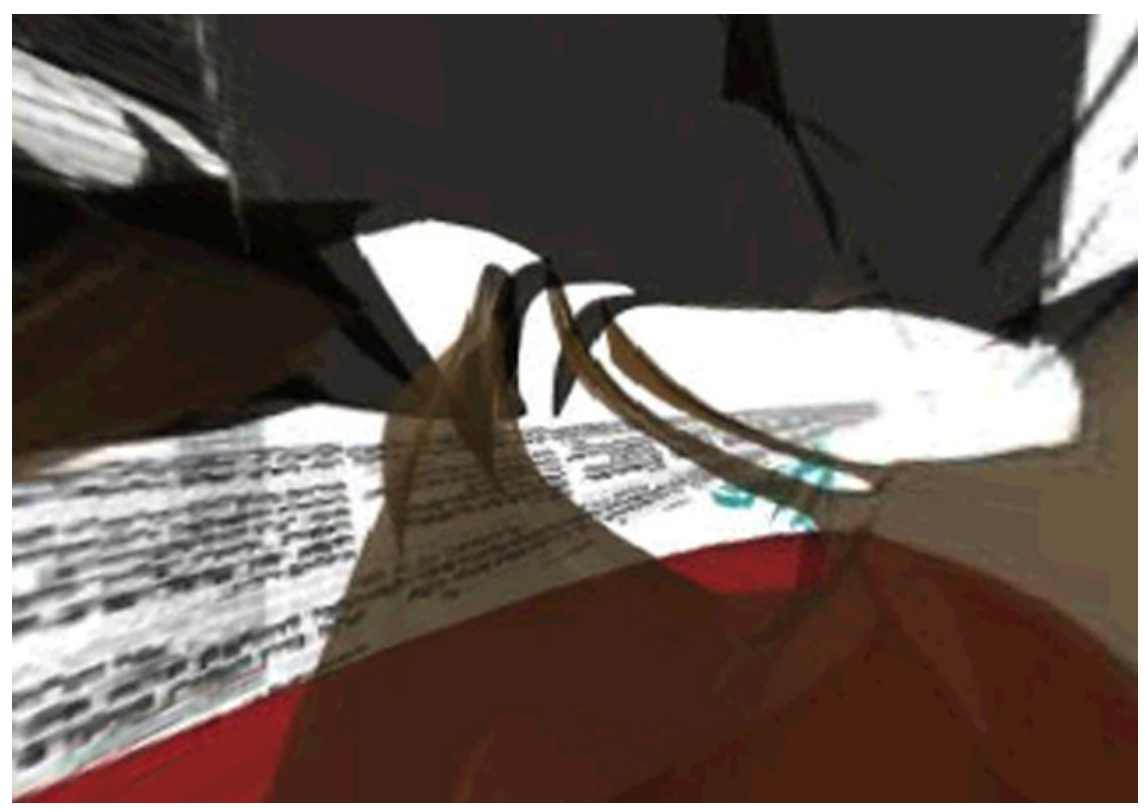

Figure 4: Digital narrative environment based on the seven days of creation in the Old Testament by student J. D. Carling.

\subsubsection{Interaction}

The level of "interaction" one has with a virtual narrative space determines how much choice one has and how one participates in the story that unfolds as one moves through the space. The ultimate in interaction is being able to shape the environment around oneself as the narrative unfolds. A majority of video games allow for elements in the virtual environment to be manipulated, whether it be ammunition which is collected, opponents that are shot and killed, or doors that can be opened and closed. Some video games now allow for the complete customization of the gaming environment, and include a "level editor" that allows for the user's own CAD models to be imported into the game. 
"First-person sensory qualities are as important as the sense of agency in creating satisfying human computer experiences. Quite simply, the experience of first-person participation tends to be related to the number, variety, and integration of sensory modalities involved in the representation. The underlying principle here is mimetic; that is, a human-computer experience is more nearly "first-person" when the activity it represents unfolds in the appropriate sensory modalities" [3].

\section{References}

[1] Toy, M., editorial in Architecture and Film, Architectural Design Magazine, London, England, 1994, p. 7.

[2] Rashid, H. and Couture, L.A., Asymptote Flux, Phaidon Press Inc, NY 2002, p. 61.

[3] Laurel, B., Computers as Theater, Addison-Wesley Publishing Company, New York, 1993, as quoted in Meadows, M., Pause \& Effect: the art of interactive narrative, New Riders Press, Indianapolis, Indiana, 2003, p. 162.

[4] Dodge, M. and Kitchin, R., Atlas of Cyberspace, Pearson Educational Press, London, 2001.

[5] Novak, M., Liquid Architectures in Cyberspace: First Steps, MIT Press, Cambridge, Massachusetts, 1991.

[6] Mitchell, W., City of Bits: Space, Place, and the Infobahn, MIT Press, Cambridge, Massachusetts, 1995.

[7] Packer, R. and Jordan, K., editors, Multimedia from Wagner to Virtual Reality, W. W. Norton \& Co., New York, New York, 2002. 